\title{
Observations on midgut of Apis mellifera workers (Hymenoptera: Apoidea) under controlled acute exposures to a Bacillus thuringiensis -based biopesticide
}

\author{
Vera D’Urso ${ }^{1}$, Gaetana Mazzeo ${ }^{2}$, Valerio Vaccalluzzo ${ }^{1}$, Giorgio SAbella ${ }^{1}$, \\ Fabio BuCChIERI ${ }^{3}$, Renata VISCuso ${ }^{1}$, Danilo G. M. VITALE ${ }^{1}$ \\ ${ }^{1}$ Dipartimento di Scienze Biologiche, Geologiche e Ambientali, Sezione di Biologia Animale "Marcello La Greca", \\ Università degli Studi di Catania, Via Androne 81, 95124, Catania, Italy \\ ${ }^{2}$ Dipartimento di Agricoltura, Alimentazione e Ambiente (Di3A), Università degli Studi di Catania, Via S. Sofia 98, \\ 95123, Catania, Italy \\ ${ }^{3}$ Istituto Euro-Mediterraneo di Scienza e Tecnologia (IEMeST), Via Emerico Amari, 123, 90139, Palermo, Italy
}

Received 6 November 2015 - Revised 31 March 2016 - Accepted 18 April 2016

\begin{abstract}
Morphostructural investigations have been carried out on Apis mellifera workers treated with single controlled acute exposures to a biopesticide containing Bacillus thuringiensis (Bt), to detect midgut changes until $96 \mathrm{~h}$. Our findings show concentration-dependence of these changes, reflecting in different degrees on both mortality and behaviour. In particular, some midgut changes are also found $96 \mathrm{~h}$ after treatment. Our results show that the tested product does not affect survival at presumable environmental concentrations, so confirming the lesser toxicity of $B t$-based biopesticides compared to other pesticides. However, in the light of the discovered long-term changes, we discuss the opportunity of taking into account possible chronic exposures to $B t$-based products on $A$. mellifera .
\end{abstract}

\section{honeybees / Bacillus thuringiensis var. aizawai/kurstaki / bioassay / mortality / morphostructural changes}

\section{INTRODUCTION}

The workers of Apis mellifera Linnaeus 1758 perform several activities, mainly aimed at collecting nectar and pollen to be used as food for their colony. The pollination activity of the foragers, moreover, plays a fundamental role in regulating reproductive processes of many plants, including those important in agriculture (Tepedino 1981; Klein et al. 2007).

Electronic supplementary material The online version of this article (doi:10.1007/s13592-016-0448-4) contains supplementary material, which is available to authorized users.

Corresponding author: D. Vitale,

danilo.vitale@unict.it

Manuscript editor: Peter Rosenkranz
Unfortunately, large-scale population decline in several species of Apoidea, including honeybees, have occurred in recent decades, also causing serious economic damage to agriculture (Biesmeijer et al. 2006; Gallai et al. 2009; vanEngelsdorp et al. 2009; Ellis et al. 2010); however, the causes of this phenomenon are still unidentified. One of the hypotheses, in this respect, is related to the use/abuse of certain pesticides in agriculture (Oldroyd 2007; vanEngelsdorp et al. 2009), considering that foraging bees could be exposed to several of these products during their activity.

In the context of the Integrated Pest Management (IPM) programme (Dent 1985), the biopesticides represent a category of less harmful products, thanks to their features, e.g., efficiency at very low concentrations, rapid inactivation and higher specificity, acting mainly on the larvae of some species of insect pests. Several strains of microorganisms are 
commonly used for biopesticides; their toxicity is different based on the target organisms (Gupta and Dikshit 2010). In particular, Bacillus thuringiensis $(B t)$ Berliner is one of the most widely used microorganisms; $B t$-based products are released into the environment through different ways (George and Crickmore 2012).

The toxic action of $B t$-based biopesticides, investigated in different species of insects, occurs during the sporulation of the bacteria, when particular toxins $(C r y)$ are produced. Cry-toxins are different protein families (insecticidal crystal proteins, ICPs) and, once in the midgut of the target organism, specifically affect the epithelium, causing a functional damage that could end with the death of the insect, according to a known mechanism of action (Percy and Fast 1983; Bravo et al. 1992; Lambert and Peferoen 1992; Knowles 1994; Gupta and Dikshit 2010; Schünemann et al. 2014).

$B t$-based biopesticides are unanimously deemed to be non-lethal to the species of Apoidea so far investigated (Bravo et al. 2011), although some studies seem to show sublethal and even long-term effects on Apis mellifera of some concentrations of $B t$ toxins, under controlled conditions (Bailey et al. 2005; Brighenti et al. 2007; Han et al. 2010; Ramirez-Romero et al. 2005, 2008). Unfortunately, despite the importance of this issue, investigations in this regard are still limited (Mommaerts et al. 2010).

Therefore, our investigation has been aimed at providing data about $A$. mellifera, by light (LM) and electronic (SEM, TEM) microscopy. For this purpose, acute single exposures to different concentrations of a $B t$-based commercial biopesticide have been performed in laboratory-controlled trials to detect any possible midgut changes in worker bees, until $96 \mathrm{~h}$.

\section{MATERIALS AND METHODS}

\subsection{Bioassay and symptoms observation}

In June 2015, workers of different ages of Apis mellifera were caught from a healthy queen-right colony of an experimental apiary (Ladurner et al. 2005; OEPP/EPPO 2010), previously prepared in a controlled field (unexposed to pesticides) near Catania (Italy).
Our acute oral toxicity assay tested one biopesticide, commonly used in Italy, with a $50 \% \mathrm{w} / \mathrm{w}$, power 25,000 $\mathrm{UI} / \mathrm{mg}$, formulation of Bacillus thuringiensis var. aizawai and kurstaki (GC-91 strain) $(46.2 \% \delta$ endotoxin and $3.8 \%$ spores in $100 \mathrm{~g}$ of wettable powder).

The bees were subdivided into four groups in which each specimen was fed with a $10-\mu \mathrm{L}$ dose of a sugary solution (s.s.) [sterilized-distilled water:honey, 1:1 (v/v); Bailey et al. 2005]: (1) "control", free of the tested biopesticide; (2) "field concentration", at field dose concentration $(100.0 \mathrm{~g} / \mathrm{hL})$ recommended on the label of the tested product; (3) "low concentration" (40.00 g/ $\mathrm{hL}$ ); and (4) "very-high concentration", at biopesticide concentration $(24,400.0 \mathrm{~g} / \mathrm{hL})$ lethal to more than $50 \%$ of the tested bees.

The trials were performed in triplicate for each group: 10 specimens were used in each group (OEPP/EPPO guidelines, 2010), for each of the three repetitions (total sum of 120 specimens, 40 for each repetition). Another separate trial replication (with all the same groups, 10 specimens per group, 40 in total sum) was contextually performed, specifically to provide specimens for LM, SEM and TEM observations.

In each trial, the 10 specimens of each group were placed in controlled cages $\left(25 \pm 2{ }^{\circ} \mathrm{C}, 60 \%\right.$ relative humidity) and isolated randomly into 10 cells ( 1 bee per cell), separated by removable dividing walls. Each bee was exposed to an artificial light (cool white, $15 \mathrm{~W}$ ) into its cell (about $1 \mathrm{~h}$ ) until the complete consumption of the $10-\mu \mathrm{L}$ dose of the s.s. (Ladurner et al. 2005). The dividing walls were then removed and a group feeder was added with the sugary solution (devoid of the tested biopesticide) and replaced every $24 \mathrm{~h}$ (OEPP-EPPO guidelines 2010). All the observations were carried out at different time intervals $(4,24,48,72$ and $96 \mathrm{~h})$ after the start of the trials to assess any long-term effect (OEPP/EPPO 2010).

\subsection{Statistical analyses}

Overall mortality analysis has been made by calculating mortality rates observed in the three different groups (Malone et al. 1999; Ladurner et al. 2005). Data on mortality rates were analyzed by means of an one-way ANOVA, followed by a LSD test (least significant difference) for homogenous groups to separate the 
mean obtained (Siscaro et al. 2006; Ruiu et al. 2007). Homogeneity of variance was assumed in all the assays. The statistical analyses were performed with STATISTICA software $\left(\right.$ Statsoft $\left.{ }^{\circledR}\right)$. Mortality rates have not been corrected with Abbott's formula (1925), since the death of the specimens of the control group was $0 \%$ (Ladurner et al. 2005).

\subsection{SEM, LM and TEM observations}

Each specimen was dissected in an insect Ringer's solution (Yamasaki and Narahashi 1963); the various midgut samples were prepared according to one of the two following methods.

\subsubsection{Scanning Electron Microscopy (SEM) preparation}

Each sample was fixed in $2.5 \%$ glutaraldehyde in a 0.1 M Sorensen's phosphate buffer (SB) with $3 \%$ sucrose, $\mathrm{pH} 7.4$, for $4 \mathrm{~h}$ at room temperature (r.t.). The samples were then washed several times in SB, dehydrated in ethyl alcohol, immersed in hexamethyldisilazane (HMDS) (Bray et al. 1993) and air-dried; finally, they were mounted on SEM stubs, metal-coated and then observed with a ZEISS EVO LS10 microscope.

\subsubsection{Light Microscopy (LM) and Transmis- sion Electron Microscopy (TEM) preparation}

Each sample was fixed in $2.5 \%$ glutaraldehyde and, in SB at r.t. The samples were then washed several times in the same buffer, post-fixed in $2 \%$ osmium tetroxide in $\mathrm{SB}$, at r.t. for $1 \mathrm{~h}$, dehydrated in ethyl alcohol, then immersed in propylene oxide and embedded in Embed 812. Semi-thin sections $(400-700 \mathrm{~nm})$ for LM observations, cut with an Ultratome III LKB, were mounted on microscope slides, deresined with a saturated solution of sodium hydroxide in absolute ethanol and stained with $0.5 \%$ Toluidine blue in SB. Ultra-thin sections $(50-70 \mathrm{~nm})$ for TEM observations, placed on copper/rhodium grids (200/ $300 \mathrm{mesh}$ ), were contrasted in uranyl acetate/lead citrate (Reynolds 1963) and then observed with a JEOL 1220 microscope.

Additional details regarding methods are available in the Supplemental Information (Online Resource 1).

\section{RESULTS}

\subsection{Statistical analyses}

Overall mortality analysis (Figure 1a) showed that the mortality rate of the low concentration group was $0 \%$, remaining unchanged for the entire observation period after treatment. The mortality rates occurred in the groups treated with field/very-high concentrations, $48 \mathrm{~h}$ after single ingestion of the solution with the biopesticide. The mortality rate of the very-high concentration group markedly increased at 72 and $96 \mathrm{~h}$ after the treatment, if compared to the respective times after treatment with the field concentration.

The one-way ANOVA followed by LSD test for homogenous group (see Table 1 in Online Resource 2) applied to the groups treated with the different concentrations $(F=6.601 ; d f=3$; $P=0.000)$ showed no difference with the control for low concentration group. As for the low and very-high concentration group, the analysis showed a significant difference with the control only for the latter group.

\subsection{Symptoms observation}

Four hours after the single ingestion of the biopesticide solution, all the specimens from field/very-high concentrations groups showed an evident hypoactivity (bees were motionless, close to the walls or at the bottom of the cage) with respect to the control group. Most of the specimens from low concentration group instead did not show sickness symptoms, keeping these conditions up to $96 \mathrm{~h}$ after treatment; however, some of them (one/two for each replication) showed the aforementioned symptoms. This stationary phase (Medrzycki et al. 2003) was also accompanied by a lower consumption of food after the treatment: the field/very-high concentration groups consumed, in fact, about 30.85 and $30.00 \%$, respectively, of the sugary solution devoid of biopesticide in the group feeder, whereas the control/low concentration groups consumed about 50.41 and $47.81 \%$, respectively.

After $24 \mathrm{~h}$, only the bees from the low/field concentration groups gradually restored their activity, although food consumption in the field 

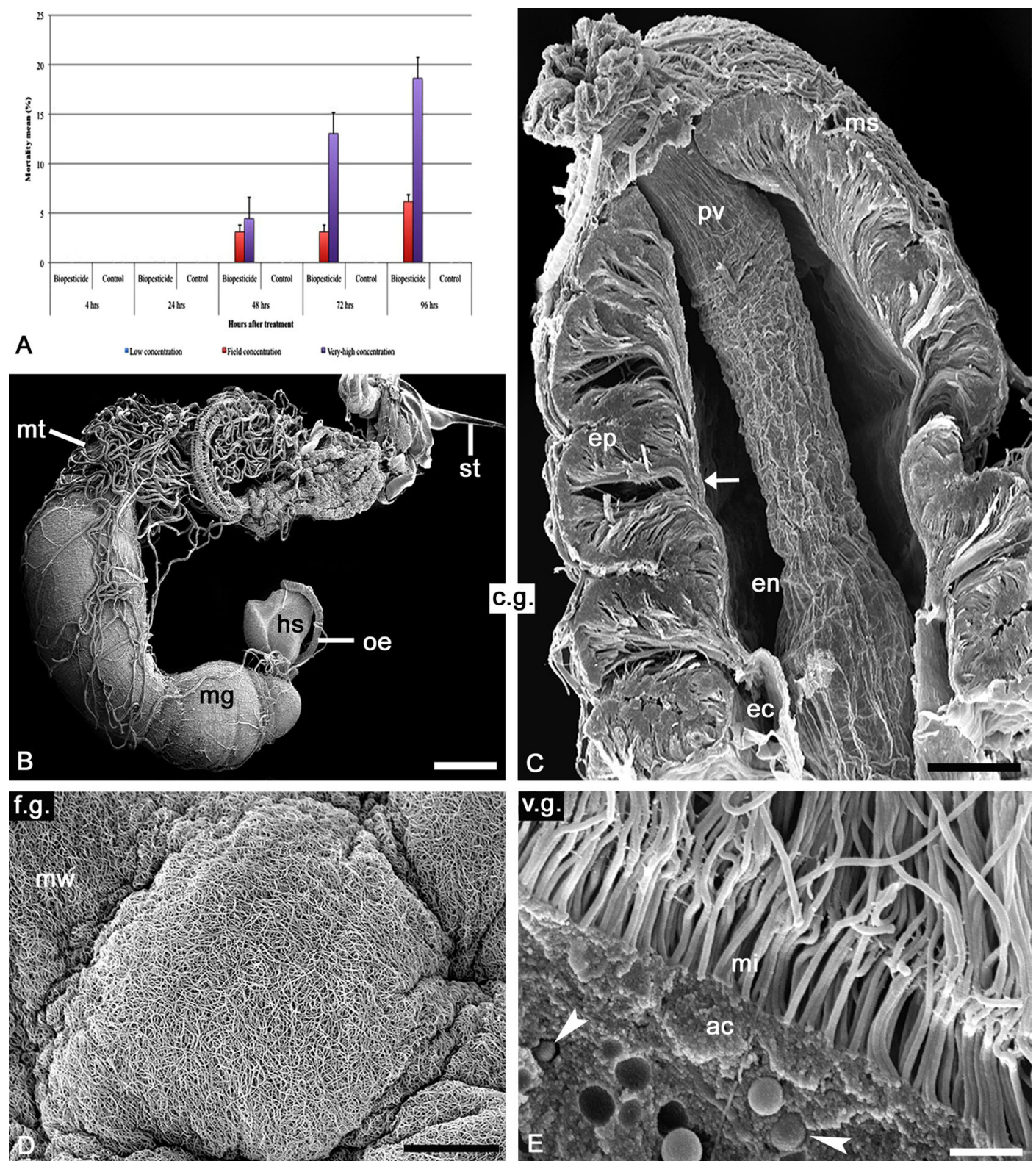

Figure 1. Mortality means (a ) and SEM midgut observations (b-e ), $4 \mathrm{~h}$ after treatment: b, c control group (c.g.); d field concentration group (f.g.); e very-high concentration group v.g.. a Mortality means (\% \pm SE) at different time intervals $(4,24,48,72$ and $96 \mathrm{~h})$ in the three treated groups and in the control group of workers of Apis mellifera . b General gut organization. $h s$ honey stomach; $m g$ midgut; $m t$ Malpighian tubules; oe oesophagus; st stinger. c Longitudinal section of a midgut. arrow peritrophic membrane (PM); ec ectoperitrophic space; en endoperitrophic space; $e p$ epithelium showing folds; $p v$ proventriculus protruding into the most anterior tract of the midgut lumen; ms muscular sheath. d Fibrillar meshwork ( $\mathrm{mw}$ ) of the PM. e Microvilli ( $\mathrm{mi}$ ) of an enterocyte. $a c$ apical cytoplasm; arrowheads vesicles with spherical granules. Scale bars (b) $1 \mathrm{~mm}$; (c) $150 \mu \mathrm{m}$; (d) $3 \mu \mathrm{m}$; (e) $1 \mu \mathrm{m}$

concentration group was lower than in the control and low concentration groups $(33.75 \%$, compared to 47.10 and $46.90 \%$, respectively); the very-high concentration group instead kept showing both hypoactivity and reduced food consumption $(30.83 \%)$. 
After 48, 72 and $96 \mathrm{~h}$, the still-living specimens from the low/field concentration groups gradually recovered their general behavioral activities. In the very-high concentration group instead the still-living specimens showed worsening of their general behavioral activity: slow and uncoordinated movements, inability to maintain proper posture, and subsequent paralysis ending with death of the specimens.

An overview of the effects observed within the groups is summarized in Table I.

\subsection{SEM, LM and TEM observations of the midgut}

Four hours after the single ingestion of the doses of the biopesticide solution, SEM observations of the midgut (Figure 1b) of all the specimens from all the groups were comparable (Figure 1c-e). These features were unmodified only in the control group 48, 72 and $96 \mathrm{~h}$ after the ingestion. In particular, $96 \mathrm{~h}$ after the treatment, the epithelium profile was irregular in some midgut areas of the specimens from the field concentration group, if compared to the control/ low concentration groups (Figure 2a, b). Moreover, numerous irregular cellular fragments of different sizes were interspersed with the fibrils of the peritrophic membrane (PM) which did not uniformly cover the epithelium surface; in the control/low concentration groups instead globular cell fragments, with almost similar diameter, were interspersed with the PM fibrils, almost uniformly covering the entire epithelial surface (Figure 2c, d).

Also, LM features were comparable $4 \mathrm{~h}$ after the single ingestion, remaining unmodified only in the control group (Figure 3a) up to $96 \mathrm{~h}$ after the treatment. After $24 \mathrm{~h}$, instead LM observations showed changes of the midgut epithelium in all the specimens treated (limited in some areas in the low concentration group, in particular): several enterocytes with a mostly vacuolated cytoplasm, nuclear swelling or piknotyc nuclei, increased apocrine secretion and increased cell elimination (Figure 3b, c). After 48, 72 and $96 \mathrm{~h}$, the findings of epithelial areas showing cytoplasm vacuolation gradually decreased, more rapidly in the low concentration group. After $96 \mathrm{~h}$, in fact, the midgut changes were confined to a very few areas (Figure 3d).

TEM observations showed that all the specimens from the three groups had enterocytes with similar ultrastructural features, up to $4 \mathrm{~h}$ after the trial start. Only the specimens from the control group showed unmodified their features up to $96 \mathrm{~h}$ after treatment, similarly to the above-mentioned SEM/LM observations (Figure 4a). All the specimens from the other two groups instead showed differences just $24 \mathrm{~h}$ after the trial start; in particular, enterocytes showing a swollen nucleus, with more or less not homogeneously dispersed chromatin, and a cytoplasm rich in mitochondria with dilated cristae (Figure 4b); other enterocytes showing their cytoplasm with some areas more or less devoid of organelles, swollen nuclei with many chromatin clumps (Figure $4 \mathrm{c}, \mathrm{d}$ ) or altered mitochondria, more gathered in their apical cytoplasm (Figure 4e). After 48, 72 and $96 \mathrm{~h}$, the observation frequency of these ultrastructural differences gradually decreased, although some of these changes were detectable in some midgut areas, even $96 \mathrm{~h}$ after treatment.

With regard to the basal plasma membrane of the enterocytes, all the specimens from the control group showed numerous deep introflections, where the fibrillar basal lamina (about $0.6 \mu \mathrm{m}$ thick) was interposed (Figure 4f), during the entire observation period. After $96 \mathrm{~h}$, in some midgut areas of the specimens from the low concentration group and in most of the midgut epithelium of the bees treated with the field concentration, instead the enterocytes showed numerous vesicles with electron-transparent content, close to the introflections of the basal plasma membrane (Figure 4g, h).

Finally, midgut microflora (unspecified bacteria/fungi, not uniformly spread) has been constantly observed in all the specimens, with a frequency higher in the specimens treated with the field concentration; bacteria were sometimes also observed in the muscular-connective sheath underlying the basal lamina (Online Resource 2: Supplemental Figure 1A-D). 
Table I. Overview table of the effects observed in the groups.

\begin{tabular}{|c|c|c|c|c|c|}
\hline Effect on & $\begin{array}{l}\text { Group } \\
\text { Time }\end{array}$ & Control & Low concentration & Field concentration & Very-high concentration \\
\hline \multirow[t]{5}{*}{ Symptoms } & $4 \mathrm{~h}$ & $\begin{array}{l}\text { Absent } \\
\text { F.C.: } 50.41 \%\end{array}$ & $\begin{array}{l}\text { Sporadic } \\
\text { (S.p.) } \\
\text { F.C.: } 47.81 \%\end{array}$ & $\begin{array}{l}\text { All the bees } \\
\text { (S.p./L.F.C.) } \\
\text { F.C.: } 30.85 \%\end{array}$ & $\begin{array}{l}\text { All the bees } \\
\text { (S.p./L.F.C.) } \\
\text { F.C.: } 30.00 \%\end{array}$ \\
\hline & $24 \mathrm{~h}$ & $\begin{array}{l}\text { Absent } \\
\text { F.C.: } 47.10 \%\end{array}$ & $\begin{array}{l}\text { Recovery } \\
\text { F.C.: } 46.90 \%\end{array}$ & $\begin{array}{l}\text { L.F.C. } \\
\text { F.C.: } 33.75 \%\end{array}$ & $\begin{array}{l}\text { (S.p./L.F.C.) } \\
\text { F.C.: } 30.83 \%\end{array}$ \\
\hline & $48 \mathrm{~h}$ & Absent & Recovery & Recovery & Worsening \\
\hline & $72 \mathrm{~h}$ & Absent & Absent & Recovery & Worsening \\
\hline & $96 \mathrm{~h}$ & Absent & Absent & Absent & Worsening \\
\hline \multirow[t]{5}{*}{ Midgut changes } & $4 \mathrm{~h}$ & Absent & Absent & Absent & Absent \\
\hline & $24 \mathrm{~h}$ & Absent & Some & Some & Several \\
\hline & $48 \mathrm{~h}$ & Absent & Few & Some & Widespread \\
\hline & $72 \mathrm{~h}$ & Absent & Sporadic & Few & Widespread \\
\hline & $96 \mathrm{~h}$ & Absent & Sporadic & Sporadic & Widespread \\
\hline
\end{tabular}

s.p. Stationary phase (Medrzycki et al. 2003); F.C. lower food consumption

An overview of the effects observed within the groups is summarized in Table I.

\section{DISCUSSION}

All of our analyses imply clear concentrationdependence between the single ingestion of the biopesticide solution and the extension degree of mortality rates, symptoms and midgut morphostructural changes. Moreover, the observed temporal trend is consistent with findings of similar previous studies on A. mellifera and other insects also exposed to Bt, var. kurstaki and/ or aizawai (Trona et al. 2004; Brighenti et al. 2007; Ruiu et al. 2012).

The midgut morphostructural changes (affecting PM and the epithelial cells) appear to be consistent with typical signs of cell oncosis/necrosis due to toxicological pathologies involving microbial toxins (Trump et al. 1997). In particular, these changes are strongly comparable with those found in similar previous investigations into the action of toxins of different bacterial strains (including $B t$ ) on the midgut of insects of different orders; these changes have been shown to involve mainly the plasma membrane of the midgut epithelial cells, so causing their osmotic shock (Bravo et al. 1992, 2011; Lambert and Peferoen 1992; Knowles 1994; Trona et al. 2004; Ruiu et al. 2007, 2012). So, we hypothesize that the changes observed in our study are closely related to Cry-toxins action, following the ingestion of a $B t$-based biopesticide solution.

In addition, as for the frequency of SEM/TEM observations of midgut microflora, higher in field concentration group, it is not possible to draw conclusions from our observations to the species composition of the microbiota. Furthermore, total bacterial community structures are thought not to be a sensitive indicator of $B t$-sublethal levels in honeybees (Babendreier et al. 2007). However, our observations cannot rule out that these observations could also be due to a higher excretion of gut content in response to the acute intoxication. Since the death of other insects treated with $B t$-toxins has been related to a septicemia caused by physiological midgut microflora (Graf 2011), similar correlations cannot be excluded for our findings of bacteria in the midgut muscular-connective sheath; epithelial alterations, in fact, "could open the way" for haemocoel invasion by these microorganisms.

We deem probable that, before the first appearance of midgut changes $(24 \mathrm{~h})$, the $B t$-toxins 


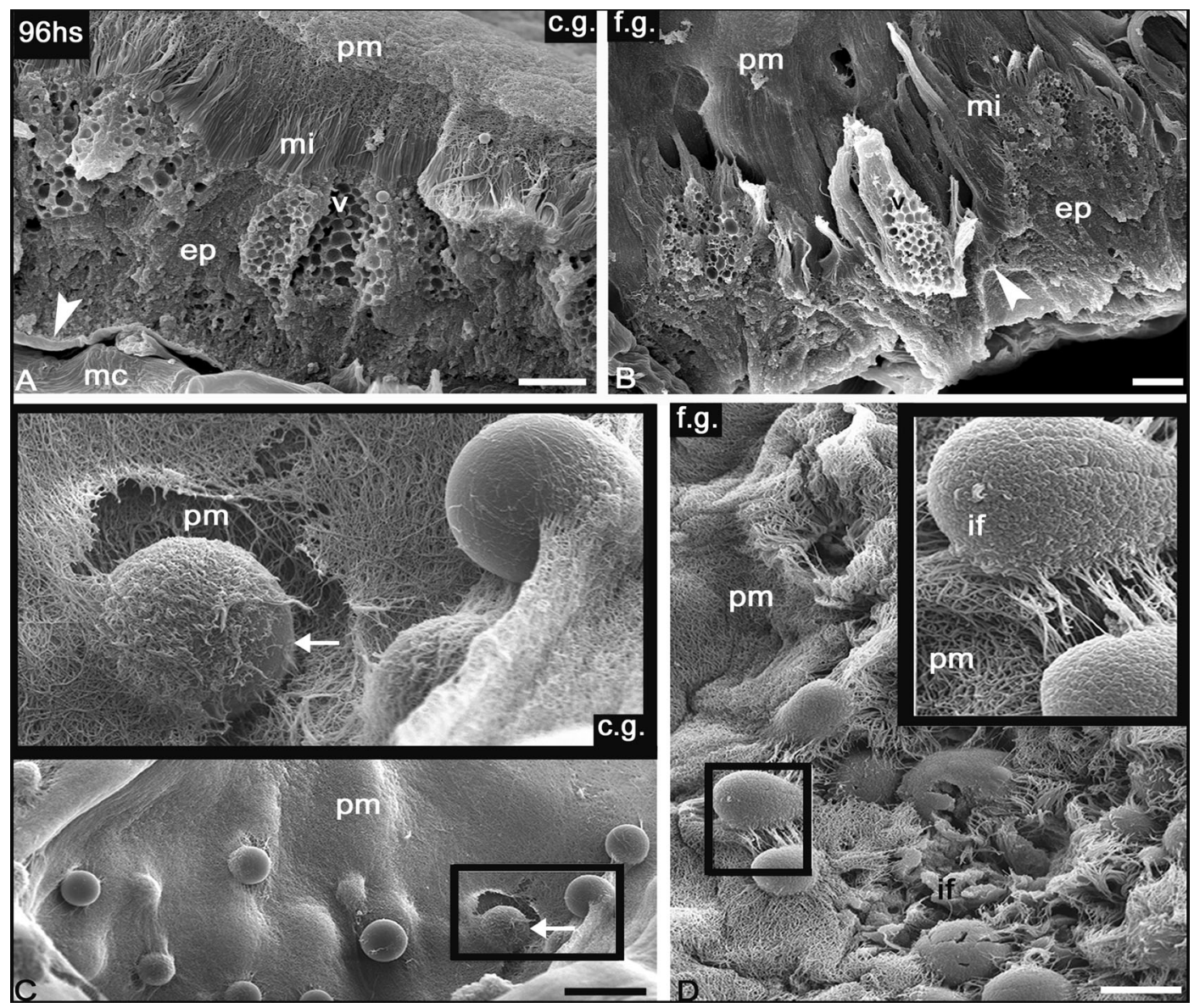

Figure 2. SEM (a-d ) observations of some midgut wall areas, $96 \mathrm{~h}$ after treatment: a, c c.g.; b , d )f.g. Regular (a) and irregular (b ) profile of two epithelial (ep) areas. arrowheads basal lamina; arrows irregular protrusion of some enterocytes; $m c$ muscular-connective sheath; $m i$ microvilli; $p m$ PM; $v$ vesicles with a spherical granule. $\mathbf{c}$ Globular cellular fragments (arrows) interspersed with the PM ( $\mathrm{pm}$ ) fibrils, uniformly covering the epithelial surface (picture in the upper black frame is a magnification of the particular in the lower frame). $\mathbf{d}$ Irregular cellular fragments (if). pm, PM, not uniformly covering the epithelium surface (picture in the big black frame is a magnification of the particular in the small frame). Scale bars (a, b ) $5 \mu \mathrm{m} ;(\mathbf{c}, \mathbf{d}) 15 \mu \mathrm{m}$

action could almost immediately modify the midgut physiology of the specimens of the groups treated with field/very-high concentrations, so affecting their behaviour just $4 \mathrm{~h}$ after treatment. The continuous action of $B t$-toxins, moreover, could justify the worsening of the symptoms in the very-high concentration group. It is reasonable, instead, that midgut changes are not particularly widespread in worker bees treated with field/low concentrations, so allowing their epithelium to rapidly restore its structural integrity/function beyond $24 \mathrm{~h}$ after treatment.
This confirms once again the fact that biopesticides represent a category of products certainly less stressful for the environment than other agrochemicals (Gupta and Dikshit 2010). Furthermore, these results are in line with previous investigations showing the high specificity of $B t$-toxins only for larvae of species of other orders of insects (Lambert and Peferoen 1992; Knowles 1994; Gupta and Dikshit 2010), and that ingestion of cotton pollen expressing CrylAc did not affect the midgut proteolytic enzyme activity (Han et al. 2012). 


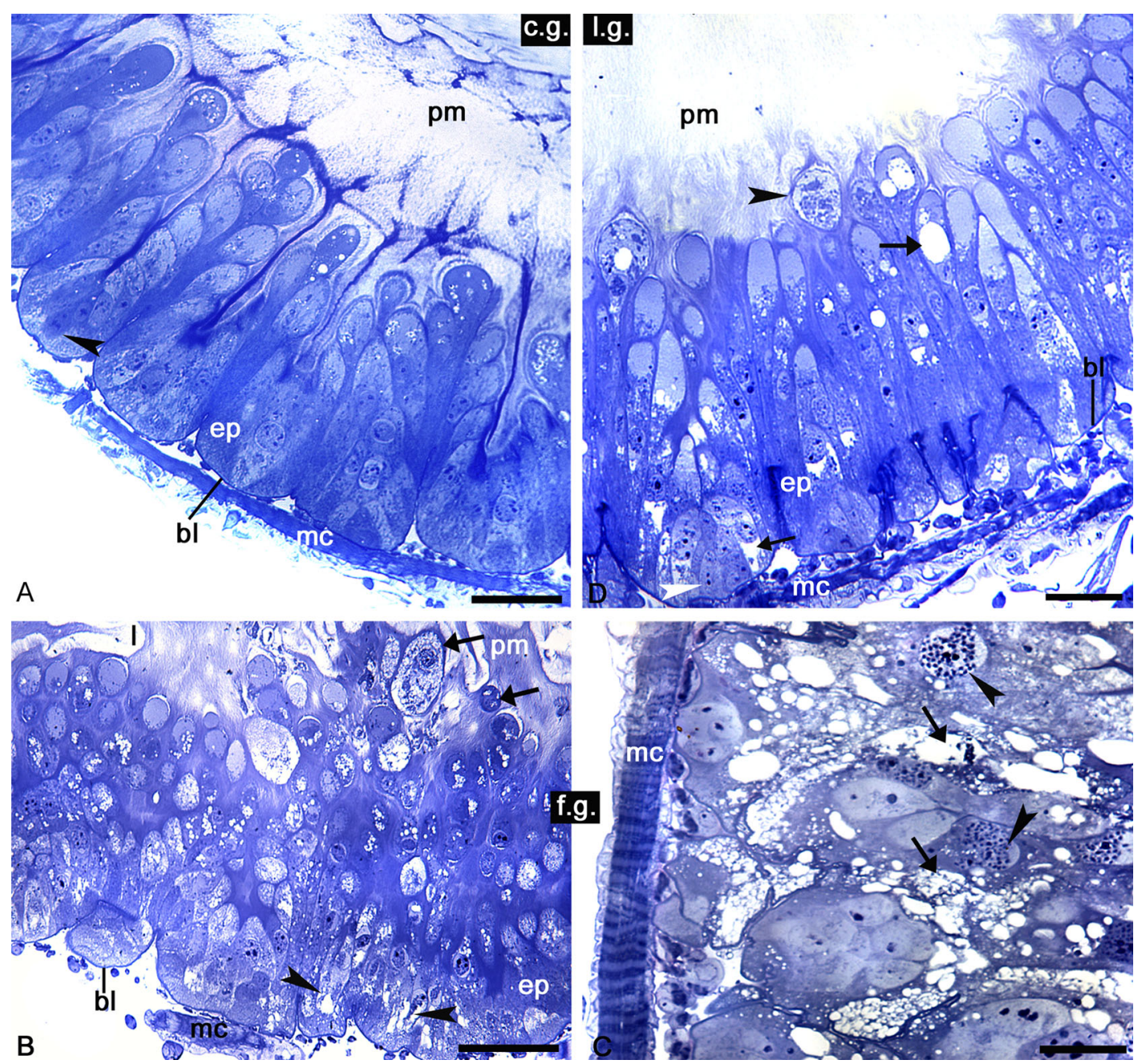

Figure 3. LM midgut observations, $24 \mathrm{~h}(\mathbf{a}-\mathbf{c})$ and $96 \mathrm{~h} \mathrm{(d)} \mathrm{after} \mathrm{treatment:} \mathrm{a} \mathrm{(c.g.);} \mathrm{b,} \mathrm{c} \mathrm{(f.g.);} \mathrm{d} \mathrm{low}$ concentration group (l.g.). Toluidine blue. a Folds of the epithelium (ep). arrowhead regenerative cell; $b l$ basal lamina; $m c$ muscular-connective sheath; $p m$ PM in the midgut lumen. b Epithelium (ep) showing numerous enterocytes with a mostly vacuolated cytoplasm (arrowheads). bl basal lamina; $l$ lumen with PM (pm) and eliminated cells (arrows); $m c$ muscular-connective sheath. c Some enterocytes with a mostly vacuolated cytoplasm (arrows) and swollen/piknotyc nuclei (arrowheads). mc muscular-connective sheath. d Folds of the epithelium (ep ) showing some enterocytes with cytoplasm vacuolization (arrows). bl basal lamina; black arrowhead eliminated cell; $m c$ muscular-connective sheath; $p m$ PM; white arrowhead regenerative cell. Scale bars: (a, d) $20 \mu \mathrm{m}$; (b ) $35 \mu \mathrm{m}$; (c) $10 \mu \mathrm{m}$.

However, the fact cannot be ignored that some behavioral symptoms (up to $24 \mathrm{~h}$ ) and/ or midgut changes (up to $96 \mathrm{~h}$ ) are found after treatment at field and even low concentrations. These findings show that single exposures to the tested $B t$-based biopesticide have somehow long-term acute effects on the behaviour and midgut epithelium of the examined bees.

It should be highlighted that $B t$-toxins are usually said to be low-level persistent in the environment (Sheeran and Fisher 1992; Lacey 2007). Secondly, bees feed on pollen/nectar, unlike larval stages of insects target of $B t$-biopesticides; 

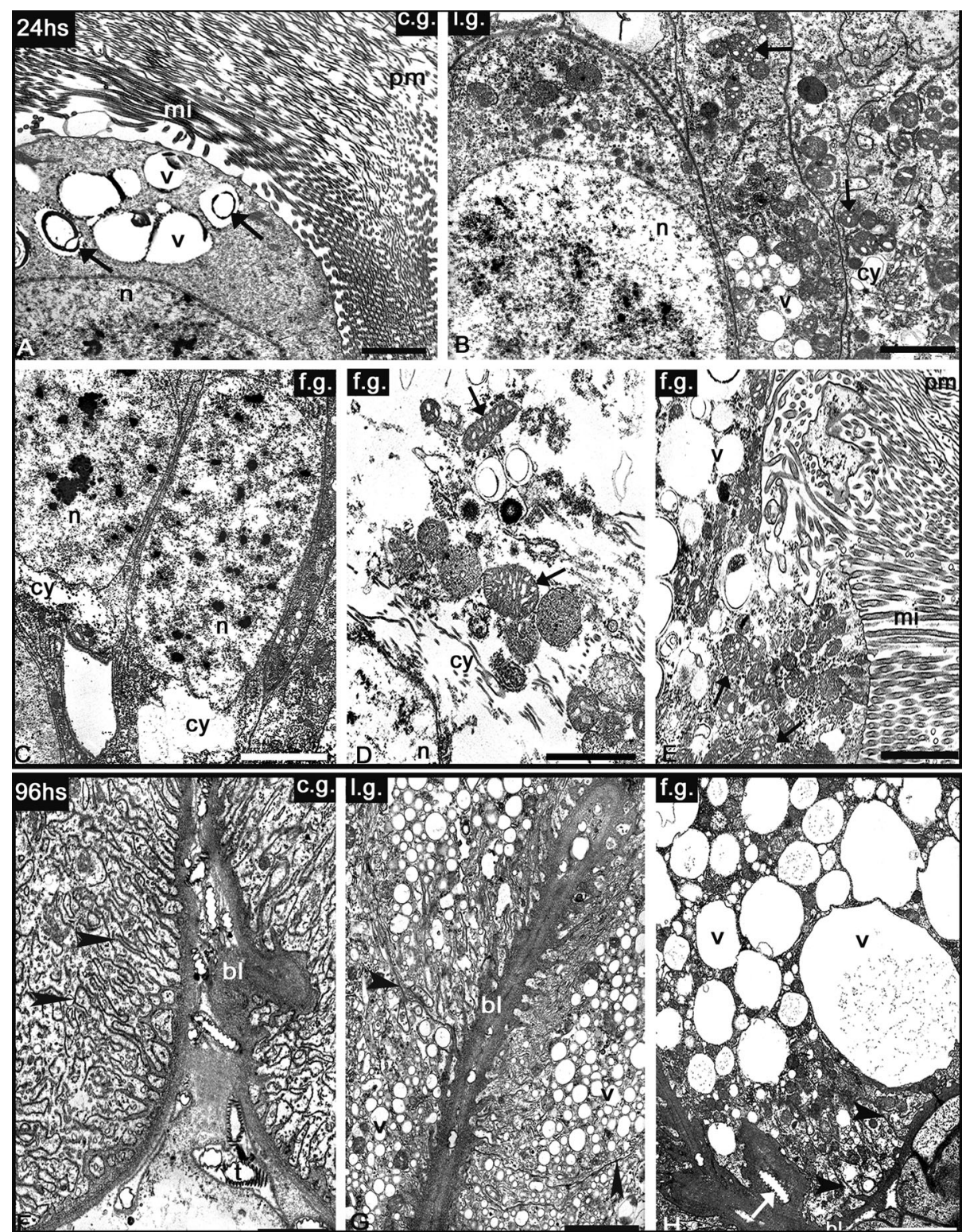

Figure 4. TEM observations of midgut wall, $24 \mathrm{~h}$ (a-e, upper square ) and $96 \mathrm{~h}$ (f-h , lower square ) after treatment: a, f) c.g.; $\mathbf{b}, \mathbf{g})$ l.g. ; $\mathbf{c}-\mathbf{e}, \mathbf{h}) f . g$. a An enterocyte showing voluminous ovoid nucleus $(n)$, with homogeneously dispersed chromatin and few small chromatin clumps. arrow spheroidal granule; $m i$ packed microvilli; $m$ PM fibrils in the lumen; $v$ vesicles. b Some enterocytes showing their cytoplasm (cy) rich in mitochondria with dilated cristae (arrowheads). $n$ swollen nucleus; $v$ vesicles. c Two enterocytes showing swollen nuclei $(n)$ with many chromatin clumps. $c y$ cytoplasm devoid of organelles. d Cytoplasm (cy) area of an enterocyte devoid of organelles and with mitochondria (arrows) showing dilated cristae. $n$ swollen nucleus. e Mitochondria (arrows), with dilated cristae, gathered in the apical cytoplasm of an enterocyte. $m$ microvilli; $p m$ PM; $v$ vesicles. $\mathbf{f}$ Deep introflections (arrowheads) of the basal plasma membrane of two enterocytes. $b l$ basal lamina; $t$ tracheole. $\mathbf{g}$ Numerous small vesicles $(v)$ close to the introflections (arrowheads) of the basal plasma membrane of two enterocytes. $b l$ basal lamina. $\mathbf{h}$ Large vesicles $(v)$ close to reduced introflections (arrowheads) of the basal plasma membrane of an enterocyte. arrow tracheole; bl basal lamina. Scale bars : $(\mathbf{a}-\mathbf{c}, \mathbf{f}-\mathbf{h})$ $2 \mu \mathrm{m} ;(\mathbf{d}, \mathbf{e}) 1.5 \mu \mathrm{m}$ 
moreover, blooming of a determined plant generally occurs just once a year. So, the environmental concentration of the biopesticide ingested by individual bees would be expected to be almost always lower than the concentration recommended on the product label ("field concentration"); furthermore, only in a restricted time-window, would bees likely be exposed to $B t$-biopesticides. Consequently, a more realistic natural scenario could be represented by the low concentration; the latter would have no significant implications on the mortality of the adult workers of A. mellifera, in spite of some changes in the midgut morphostructure.

However, since previous studies have reported long-term environmental persistence of $B t$ cells/toxins, and bioaccumulation and changes in foraging/learning activity of bees treated with Bt-toxins (Vettori et al. 2003; Babendreier et al. 2005; Clark et al. 2005; Ramirez-Romero et al. 2005, 2008; Tetreau et al. 2012; Strain and Lydy 2015), our findings lead us to ponder on the worst case scenario of chronic toxicity following repeated ingestions, even at a probable environmental dilution of the $B t$-product.

With the aim of deciding whether the tested product can be properly deemed non-lethal at the concentration suggested on the product label, we are carrying out further ongoing investigations, both in controlled trials and in natural conditions. Any chronic toxicity of $B t$ product has to be assessed as to whether it is affecting worker bees and their important role for the colony, especially for the larvae. These studies are also necessary in the light of the "monarch butterfly controversy" about the presumed toxic effects of $B t$ in controlled trials (Shelton and Sears 2001). Further investigations should also have to focus on other aspects. Based on the trophic behaviour in a honeybee colony (De Marco and Farina 2003), the dynamics of the less probable (but not impossible) case of repeated Bt toxins' indirect transmission to other bees of a colony should be studied. Finally, since certain Bttoxins concentrations have been shown to affect the reproductive rate of Bombus terrestris (Mommaerts et al. 2010), any possible effect on the reproductive systems should also be investigated in A. mellifera.

Additional Results (particularly, about midgut changes in specimens treated with very high concentration), Discussion and Figures are available in the Supplemental Information (Online Resources 1 and 2, Supplemental Figure 2A - F).

\section{ACKNOWLEDGMENTS}

We thank Prof. V. Arizza and Prof. G. Zummo (respectively of Dipartimento di Scienze e Tecnologie biologiche, chimiche e farmaceutiche and Dipartimento di Biomedicina sperimentale e neuroscienze cliniche, University of Palermo, Sicily) for their full availability. We also thank Dr. G. Fichera (Dipartimento di Scienze Biologiche, Geologiche e Ambientali, Orto Botanico, University of Catania, Sicily) for having allowed us SEM observations.

Observations sur I'intestin moyen d'ouvrières d'Apis mellifera (Hymenoptera: Apoidea) soumises à des expositions fortes et contrôlées à un biopesticide à base de Bacillus thuringiensis

abeille / essai biologique / Bt. var. aizawai / Bt. var. kurstaki / mortalité / modifications morphologiques

Beobachtungen am Mitteldarm von Apis mellifera Arbeiterinnen (Hymenoptera: Apoidea) nach kontrollierter akuter Exposition gegenüber einem $B a$ cillus thuringiensis Biopestizid

Honigbienen / Bacillus thuringiensis var. aizawai / kurstaki / Biotest / Mortalität / morphologische Veränderungen

\section{REFERENCES}

Abbott, W.S. (1925) A method of computing the effectiveness of an insecticide. J. Econ. Entomol. 18, 65-267

Babendreier, D., Kalberer, N.M., Romeis, J., Fluri, P., Mulligan, E., Bigler, F. (2005) Influence of Bt-transgenic pollen, Bt-toxin and protease inhibitor (SBTI) ingestion on development of the hypopharyngeal glands in honeybees. Apidologie 36, 585-594

Babendreier, D., Joller, D., Romeis, J., Bigler, F., Widmer, F. (2007) Bacterial community structures in honeybee intestines and their response to two insecticidal proteins. FEMS Microbiol. Ecol. 59, 600-610 
Bailey, J., Scott-Dupree, C., Harris, R., Tolman, J., Harris, B. (2005) Contact and oral toxicity to honey bees (Apis mellifera) of agents registered for use for sweet corn insect control. Apidologie 36, 623-633

Biesmeijer, J.C., Roberts, S.P.M., Reemer, M., Ohlemüller, R., Edwards, M., Peeters, T., Schaffers, A.P., Potts, S.G., Kleukers, R., Thomas, C.D., Settele, J., Kunin, W.E. (2006) Parallel declines in pollinators and insectpollinated plants in Britain and the Netherlands. Science $\mathbf{3 1 3}, 351-354$

Bravo, A., Hendrickx, K., Jansens, S., Peferoen, M. (1992) Immunocytochemical analysis of specific binding of Bacillus thuringiensis insecticidal crystal proteins to lepidopteran and coleopteran midgut membranes. J. Invertebr. Pathol. 60, 247-253

Bravo, A., Likitvivatanavong, S., Gill, S.S., Soberón, M. (2011) Bacillus thuringiensis : a story of a successful bioinsecticide. Insect Biochem. Molec. 41, 423-431

Bray, D.F., Bagu, J., Koegler, P. (1993) Comparison of hexamethyldisilazane (HMDS), Peldri II, and criticalpoint drying methods for scanning electron microscopy of biological specimens. Microsc. Res. Techniq. 28, 48-495

Brighenti, D.M., Carvalho, C.F., Carvalho, G.A., Brighenti, C.R.G., Carvalho, S.M. (2007) Bioatividade do Bacillus thuringiensis var. kurstaki (Berliner, 1915) para adultos de Apis mellifera Linnaeus, 1758 (Hymenoptera: Apidae). Ciênc. Agrotecnol. 31 , 279-289

Clark, B.W., Phillips, T.A., Coats, J.R. (2005) Environmental fate and effects of Bacillus thuringiensis (Bt) proteins from transgenic crops: a review. J. Agric. Food Chem. 53 , 4643-4653

De Marco, R.J., Farina, W.M. (2003) Trophallaxis in forager honeybees (Apis mellifera): resource uncertainty enhances begging contacts? J. Comp. Physiol. A. 189, $125-134$

Dent, D. (1985) Integrated pest management. Chapman and Hall. $356 \mathrm{pp}$

Ellis, J.D., Evans, J.D., Pettis, J. (2010) Colony losses, managed colony population decline, and colony collapse disorder in the United States. J. Apic. Res. 49, 134-136

Gallai, N., Salles, J.M., Settele, J., Vaissière, B.E. (2009) Economic valuation of the vulnerability of world agriculture confronted with pollinator decline. Ecol. Econ. 68, 810-821

George, Z., Crickmore, N. (2012) Chapter 2. Bacillus thuringiensis . Applications in Agriculture. In: Bacillus thuringiensis Biotechnology., Estibaliz Sansinenea Editor, pp. 19-39

Graf, J. (2011) Shifting paradigm on Bacillus thuringiensis toxin and a natural model for Enterococcus faecalis septicemia. mBio 2(4), e00161-11. doi:10.1128/ mBio.00161-11

Gupta, S., Dikshit, A.K. (2010) Biopesticides: an ecofriendly approach for pest control. J. Biopest. 3, 186-188

Han, P., Niu, C.Y., Lei, C.L., Cui, J.J., Desneux, N. (2010) Quantification of toxins in a Cry1Ac+CpTI cotton cultivar and its potential effects on the honey bee Apis mellifera L. Ecotoxicology 19, 1452-1459

Han, P., Niu, C.Y., Biondi, A., Desneux, N. (2012) Does transgenic Cry $1 \mathrm{Ac}+\mathrm{CpTI}$ cotton pollen affect hypopharyngeal gland development and midgut proteolytic enzyme activity in the honey bee Apis mellifera L. (Hymenoptera, Apidae)? Ecotoxicology 21, 2214-2221

Klein, A.-M., Vaissiere, B.E., Cane, J.H., SteffanDewenter, I., Cunningham, S.A., Kremen, C., Tscharntke, T. (2007) Importance of pollinators in changing landscapes for world crops. P. R. Soc. Lond. B Bio. 274 (1608), 303-313

Knowles, B.H. (1994) Mechanism of action of Bacillus thuringiensis insecticidal d-endotoxins. Adv. Insect Physiol. 24, 75-308

Lacey, L.A. (2007) Bacillus thuringiensis serovariety israelensis and Bacillus sphaericus for mosquito control. J. Am. Mosq. Control. Assoc. 23 , 133-163

Ladurner, E., Bosch, J., Maini, S., Kemp, W.P. (2005) Assessing delayed and acute toxicity of five formulated fungicides to Osmia lignaria Say and Apis mellifera. Apidologie 36, 449-460

Lambert, B., Peferoen, M. (1992) Insecticidal promise of Bacillus thuringiensis. Bioscience 42, 112-122

Malone, L.A., Burgess, E.P.J., Stefanovic, D. (1999) Effects of a Bacillus thuringiensis toxin, two Bacillus thuringiensis biopesticide formulations, and a soybean trypsin inhibitor on honey bee (Apis mellifera L.) survival and food consumption. Apidologie 30, 465-473

Medrzycki, P., Montanari, R., Bortolotti, L., Sabatini, A.G., Maini, S., Porrini, C. (2003) Effects of imidacloprid administered in sub-lethal doses on honey bee behaviour. Laboratory tests. Bull. Insectol. 56, 59-62

Mommaerts, V., Jans, K., Smagghe, G. (2010) Impact of Bacillus thuringiensis strains on survival, reproduction and foraging behaviour in bumblebees (Bombus terrestris ). Pest Manag. Sci. 66, 520-525

OEPP/EPPO (2010) Guideline for the efficacy evaluation of plant protection products. Side-effects on honeybees. Directive PP 1/170 (2). Bull. OEPP/EPPO Bull. 40, 313-319

Oldroyd, B.P. (2007) What's killing American honey bees? PLoS Biol. 5(6), e168. doi:10.1371/ journal.pbio.005016

Percy, J., Fast, P.G. (1983) Bacillus thuringiensis crystal toxin: Ultrastructural studies of its effect on silkworm midgut cells. J. Invertebr. Pathol. 41, 86-98

Ramirez-Romero, R., Chaufaux, J., Pham-Delègue, M.H. (2005) Effects of Cry $1 \mathrm{Ab}$ protoxin, deltamethrin and imidacloprid on the foraging activity and the learning performances of the honeybee Apis mellifera, a comparative approach. Apidologie 36, 601-611

Ramirez-Romero, R., Desneux, N., Decourtye, A., Chaffiol, A., Pham-Delègue, M.H. (2008) Does $\mathrm{Cry} 1 \mathrm{Ab}$ protein affect learning performances of the honey bee Apis mellifera L. (Hymenoptera, Apidae)? Ecotoxicol. Environ. Saf. 70, 327-333 
Reynolds, E.S. (1963) The use of lead citrate at high $\mathrm{pH}$ as an electron opaque stain in electron microscopy. J. Cell Biol. 7, 208-212

Ruiu, L., Floris, I., Satta, A., Fois, X. (2007) Susceptibility of the honeybee (Apis mellifera L.) to entomopathogenic bacterial toxins used for the biological control. Redia XC, 87-90

Ruiu, L., Satta, A., Floris, I. (2012) Observations on house fly larvae midgut ultrastructure after Brevibacillus laterosporus ingestion. J. Invertebr. Pathol. 111 , 211-216

Schünemann, R., Knaak, N., Fiuza, L.M. (2014) Mode of action and specificity of Bacillus thuringiensis toxins in the control of caterpillars and stink bugs in soybean culture. ISRN Microbiol. . doi:10.1155/2014/135675

Sheeran, W., Fisher, S.W. (1992) The effects of agitation, sediment, and competition on the persistence and efficacy of Bacillus thuringiensis var israelensis (Bti). Ecotoxicol. Environ. Saf. 24, 338-346

Shelton, A.M., Sears, M.K. (2001) The monarch butterfly controversy: scientific interpretations of a phenomenon. Plant J. 27, 483-488

Siscaro, G., Longo, S., Mazzeo, G., Suma, P., Zappalà, L., Samperi, G. (2006) Side-effects of insecticides on natural enemies of citrus scale pests in Italy. Integrated control in citrus fruit crops. IOBC-WPRS Bull. 29, 55-64

Strain, K.E., Lydy, M.J. (2015) The fate and transport of the $\mathrm{Cry} 1 \mathrm{Ab}$ protein in an agricultural field and laboratory aquatic microcosms. Chemosphere 132, 94-100

Tepedino, V.J. (1981) The pollination efficiency of the squash bee (Peponapis pruinosa) and the honey bee
(Apis mellifera) on summer squash (Cucurbita pepo). J. Kansas Entomol. Soc. 54, 359-377

Tetreau, G., Alessi, M., Veyrenc, S., Périgon, S., David, J.P., Reynaud, S., Després, L. (2012) Fate of Bacillus thuringiensis subsp. israelensis in the field: evidence for spore recycling and differential persistence of toxins in leaf litter. Appl. Environ. Microbiol. 78, 8362-8367

Trona, F., Ruiu, L., Floris, I., Solinas, M. (2004) Comparative behavioural and anatomo-pathological investigations on Musca domestica L. Adults treated with a new strain of Bacillus sp. close related to B. thuringiensis (Berliner). Entomologica 38, 49-73

Trump, B.F., Berezesky, I.K., Chang, S.H., Phelps, P.C. (1997) The pathways of cell death: oncosis, apoptosis, and necrosis. Toxicol. Pathol. 25, 82-88

vanEngelsdorp, D., Evans, J.D., Saegerman, C., Mullin, C., Haubruge, E., Nguyen, B.K., Frazier, M., Frazier, J., Cox-Foster, D., Chen, Y., Underwood, R., Tarpy, D.R., Pettis, J.S. (2009) Colony collapse disorder: a descriptive study. PLoS ONE 4(8), e6481. doi:10.1371/ journal.pone.0006481

Vettori, C., Paffetti, D., Saxena, D., Stotzky, G., Giannini, R. (2003) Persistence of toxins and cells of Bacillus thuringiensis subsp. kurstaki introduced in sprays to Sardinia soil. Soil Biol. Biochemical 40, 1-10

Yamasaki, T., Narahashi, T. (1963) In: Fukaya, M., Ishii, S., Yamasaki, T. (eds.) Laboratory guide for applied entomologists, p. 858. Nihon Shokubutsu Boeki Kyokai, Tokyo 